\title{
Evaluation of Fundoscopic Abnormalities in Patients with Coronary Artery Disease
}

\author{
Tolga Doğan ${ }^{1}$, Macit Kalçık¹, Mucahit Yetim , Özgür Yalçınbayır², Lütfü Bekar ${ }^{1}$, Oğuzhan Çelik³ , Osman \\ Akın Serdar ${ }^{4}$ \\ ${ }^{1}$ Department of Cardiology, Hitit University Faculty of Medicine, Çorum, Turkey \\ ${ }^{2}$ Department of Ophthalmology. Uludag University School of Medicine, Bursa, Turkey \\ ${ }^{3}$ Department of Cardiology, Muğla Sttkı Koçman University Training and Research Hospital, Muğla, Turkey \\ ${ }^{4}$ Department of Cardiology. Uludag University School of Medicine, Bursa, Turkey
}

Received: 24 March 2019, Accepted: 02 April 2019, Published online: 28 April 2019

(C) Ordu University Institute of Health Sciences, Turkey, 2019

\begin{abstract}
Objective: Coronary artery disease (CAD) is the leading cause of death in the world. There has been recent interest to microvasculature changes that are involved in systemic conditions associated with CAD. Retinal microvascular changes which can be easly detected noninvasively may be also a marker for cardiovascular diseases. Our aim in this study was to evaluate the relationship between the retinal findings and CAD by performing fundoscopic examination in patients diagnosed with CAD.

Methods: This study enrolled 100 patients (72 female, mean age: 59.3 \pm 7.1 years) diagnosed with CAD, along with 100 controls ( 75 female, mean age: $57.8 \pm 8.2$ years) who were proved to have normal coronary arteries by coronary angiography. Bilateral fundoscopic examination was performed in all study population. Fundoscopic findings and risk factors for CAD were compared between the groups.

Results: There was no significant difference between the groups in terms of clinical, demographical and laboratory characteristics of the patients. The prevalence of atherosclerotic changes was significantly higher in patients with CAD than controls ( 87 vs $58 \%, \mathrm{p}<0.001)$. Hypertensive retinopathy was observed more frequently in CAD group as compared to controls (95 vs $60 \%, \mathrm{p}<0.001)$. The prevalence of diabetic retinopathy, retinal vein occlusion, retinal collateral vessels, increased retinal tortuosity, Drusenoid bodies and Hollenhorst plaques were similar between the groups.

Conclusion: The atherosclerotic and hypertensive retinal findings were more frequently observed in patients with CAD. Therefore, fundoscopic examination may be useful in the evaluation of such patients with CAD. Key words: Coronary artery disease, fundoscopic examination, atherosclerosis.
\end{abstract}

Suggested Citation: Doğan T, Kalçık M, Yetim M, Yalçınbayır Ö, Bekar L, Çelik O, Serdar OA. Evaluation of Fundoscopic Abnormalities in Patients with Coronary Artery Disease. Middle Black Sea Journal of Health Science, 2019; 5(1): 26-32

Address for correspondence/reprints:

Tolga Doğan

Telephone number: +90 (505) 5772716

E-mail: drtolgad@gmail.com

DOI: $10.19127 / \mathrm{mbsjohs} .543978$

\section{Introduction}

Currently, coronary artery disease (CAD) is the leading cause of death in our country and in the world (Bonow et al.,2002). Hypertension, dyslipidemia, diabetes mellitus, obesity, and smoking are traditional risk factors that were accused to cause CAD in most cases (Wilson et al., 1998; Smith 2006). However, 15-20\% of those with CAD have no identified traditional risk factors (Humphrey et al., 2008). There has been recent interest to microvasculature changes that are involved in systemic conditions associated with 
CAD. Blood flow disturbances and vascular changes in ocular circulation in patients with $\mathrm{CAD}$ can lead to abnormal retinal findings. Retinal microvascular abnormalities which can be easly detected noninvasively reflect cumulative microvascular injury and may indicate the relationship between microvascular pathologies and cardiovascular diseases (Goto et al., 1975). Potential links between retinal findings and CAD would have important clinical implications, as individuals with abnormal findings in the retinal microvasculature could be screened or monitored for development of CAD. In this study, we aimed to evaluate the relationship between the retinal findings and $\mathrm{CAD}$ by performing fundoscopic examination in patients diagnosed with $\mathrm{CAD}$.

\section{Methods}

\section{Study design and subjects}

This single-center study enrolled 100 patients (72 female, mean age: $59.3 \pm 7.1$ years) diagnosed with CAD, along with 100 controls (75 female, mean age: $57.8 \pm 8.2$ years) who were proved to have normal coronary arteries by coronary angiography. The blood pressure values were measured following a resting period of ten minutes in the sitting position from the right arm using an appropriate cuff size. The patients who had a systolic blood pressure of $\geq 140 \mathrm{mmHg}$ and/ or diastolic blood pressure of $\geq 90$ $\mathrm{mmHg}$ and who were using antihypertensive medication were considered as hypertensive (Tedeschi-Reiner et al., 2005). Diabetes mellitus was diagnosed if subjects were on drug treatment for diabetes (insulin or oral antidiabetic agents) and/or fulfilled the criteria laid down by the World Health Organization Consulting Group report (i.e., a fasting venous blood glucose level of $>126 \mathrm{mg} / \mathrm{dL}$ and/or a 2 -h postglucose value of $>200 \mathrm{mg} / \mathrm{dL}$ ) (Alberti and Zimmet 1988). The coronary risk factors were evaluated separately in the patients who were included in the study. All fundoscopic and demographic parameters including traditional risk factors for CAD were recorded into a dataset and compared between CAD patients and controls. All patients provided a written informed consent and the study protocol was approved by the local ethics committee of the hospital in accordance with the Declaration of Helsinki and Good Clinical Practice guidelines.

\section{Fundoscopic examination}

The patients were evaluated in the Opthalmology Retina Outpatient Clinic. Fundoscopic examination was performed in both eyes by the same opthalmologist using Zeiss FF 450 Plus IR fundus camera (Carl Zeiss, Meditec Inc. Jena, Germany). The opthalmologist did not know any data about the subjects, particularly their coronary artery condition. Before the procedure, both pupils were dilated using Tropamid Fort $\% 1$ eye drop. The extent and severity of atherosclerotic vascular lesions in the retinal arteries were classified according to the Scheie classification (Scheie 1953). Grade 1 is a broadening of the light reflex from the artery, with scanty or no arteriovenous compression (earliest sign of retinal artery atherosclerosis). Grade 2 is the same as stage 1, but more prominent. In Grade 3, the arteries have a "copper wire" pattern, the arteriovenous compression is much greater and severe atherosclerotic changes of the retinal arteries are seen. In Grade 4, the arteries have a "silver wire" pattern and the arteriovenous crossing changes are the most serious (Hubbard et al., 1999; Wong et al., 2001).

\section{Coronary angiography}

Coronary angiography was performed by clinical indications such as abnormal stress test results, positive treadmill test, dobutamine stress echo, typical chest pain, or signs of ischemia during myocardial perfusion scintigraphy. All study population underwent selective coronary artery angiography after appropriate patient preparation. Femoral artery and sometimes radial or brachial artery cannulation was used for the arterial access site and a Judkins system was applied for cannulation of the left and right coronary arteries. Coronary angiographies were evaluated by at least two independent interventional cardiologists. Presence of $25 \%$ or more stenosis in the major epicardial arteries on coronary angiography was considered CAD (Baim and Grossmann 2000). Presence of less than 50 stenosis in the epicardial coronary arteries and/or lateral CAD (having a diameter of less than $2 \mathrm{~mm}$ and supplying a small myocardial area) was considered non-critical CAD.

\section{Laboratory analysis}

In order to perform complete blood count and blood chemistry panel, venous blood samples were collected after 12-hours of fasting by a clean puncture of an antecubital vein from all patients. Complete blood countings, fasting blood glucose, urea, creatinine, $\mathrm{HbAlc}$, serum reactive protein (CRP), erythrocyte sedimentation rate (ESR), total cholesterol (TC), high-density lipoprotein (HDL), and triglyceride (TG) levels were measured. Lowdensity lipoprotein (LDL), was calculated using the 
Friedewald formula [LDL $(\mathrm{mg} / \mathrm{dL})=\mathrm{TC}-(\mathrm{HDL}+$ TG/5)] (Friedewald 1972).

\section{Statistical analysis}

Statistical analyses were performed using IBM SPSS Statistics for Windows, Version 19.0. (IBM Corp. Armonk, NY). The variables were investigated using analytical methods (Kolmogorov-Smirnov/Shapiro-Wilk test) to determine whether or not they were approximately normally distributed. Descriptive statistics were reported as mean with standard deviation for continuous variables with normal distribution, median and $25^{\text {th }}-75^{\text {th }}$ percentile values for continuous variables without normal distribution, and frequencies with percentages for the categorical variables. Group comparisons for continuous variables were tested using Student $t$ test when data distribution was normal and using Mann-Whitney U test when data distributions were not normal. Comparisons for categorical variables were evaluated by chi-square test. Significance level was accepted as $\mathrm{p}<0.05$ in all statistical analyses.

\section{Results}

The clinical, demographical, laboratory characteristics and medications of patients with and without CAD were presented in Table 1 . There was no significant difference between the groups in terms of age, gender, frequency of diabetes mellitus, hypertension, dyslipidemia, smoking status and family history of CAD. Body mass index, systolic and diastolic blood pressures were also similar between the groups. Upon comparison of laboratory parameters between CAD group and controls, there was no significant difference in terms of hemoglobin, fasting blood glucose, urea, creatinine, HbA1c, CRP, ESR, TC, HDL, LDL, and TG levels between the groups.

Retinal findings which were found during fundoscopic examination were presented in Table 2. Atherosclerotic changes were observed in $87 \%$ of the patients with CAD and in $58 \%$ of the controls. Among patients with CAD, Grade I atherosclerosis was found in $54 \%$, grade II atherosclerosis was found in $32 \%$ and grade III atherosclerosis was found in $1 \%$. Grade IV atherosclerosis was not found. However, among contol group, Grade I atherosclerosis was found in $39 \%$ and grade II atherosclerosis was found in $19 \%$.
Table 1: Comparison of baseline demographic characteristics, laboratory findings and medications between patients with CAD and controls

\begin{tabular}{|l|c|c|c|}
\hline $\begin{array}{l}\text { Demographic } \\
\text { Characteristics }\end{array}$ & $\begin{array}{c}\text { CAD } \\
\text { Group } \\
(\mathbf{n = 1 0 0})\end{array}$ & $\begin{array}{c}\text { Controls } \\
(\mathbf{n = 1 0 0})\end{array}$ & $\begin{array}{c}\text { P } \\
\text { value }\end{array}$ \\
\hline Gender (female) & $72(72)$ & $75(75)$ & 0.631 \\
\hline Age (years) & $59.3 \pm 7.1$ & $57.8 \pm 8.2$ & 0.165 \\
\hline Hypertension, n(\%) & $70(70)$ & $59(59)$ & 0.104 \\
\hline $\begin{array}{l}\text { Diabetes Mellitus, } \\
\text { (\%) }\end{array}$ & $26(26)$ & $20(20)$ & 0.313 \\
\hline Dyslipidemia, n(\%) & $39(39)$ & $29(29)$ & 0.136 \\
\hline $\begin{array}{l}\text { Smoking Status, } \\
\text { n(\%) }\end{array}$ & $21(21)$ & $14(14)$ & 0.193 \\
\hline $\begin{array}{l}\text { Familial history of } \\
\text { CAD*, n }(\%)\end{array}$ & $22(22)$ & $18(18)$ & 0.480 \\
\hline BMI* (kg/m²) & $29.1 \pm 4.4$ & $28.7 \pm 3.6$ & 0.829 \\
\hline SBP* $\left.(\mathrm{mmHg})^{2}\right)$ & $133.1 \pm 17.7$ & $129.7 \pm 15.6$ & 0.488 \\
\hline DBP* (mmHg) & $77.7 \pm 12.3$ & $80.4 \pm 17.5$ & 0.257 \\
\hline
\end{tabular}

\begin{tabular}{|l|c|c|c|}
\hline \multicolumn{4}{|l}{$\begin{array}{l}\text { Laboratory } \\
\text { Parameters }\end{array}$} \\
\hline Glucose (mg/dL) & $109.8 \pm 48.9$ & $113.1 \pm 44.8$ & 0.643 \\
\hline Urea (mg/dL) & $35.5 \pm 18.3$ & $36.2 \pm 13.1$ & 0.795 \\
\hline Creatinine (mg/dL) & $1.04 \pm 0.43$ & $1.03 \pm 0.41$ & 0.868 \\
\hline HbA1c (\%) & $6.42 \pm 1.31$ & $6.27 \pm 1.23$ & 0.682 \\
\hline $\begin{array}{l}\text { Total cholesterol } \\
\text { (mg/dL) }\end{array}$ & $173.8 \pm 43.6$ & $171.4 \pm 42.9$ & 0.698 \\
\hline HDL* (mg/dL) & $40.8 \pm 9.9$ & $39.1 \pm 8.3$ & 0.170 \\
\hline LDL* (mg/dL) & $102.5 \pm 33.8$ & $105.5 \pm 32.9$ & 0.522 \\
\hline $\begin{array}{l}\text { Triglyceride } \\
\text { (mg/dL) }\end{array}$ & $153.8 \pm 77.5$ & $141.3 \pm 59.9$ & 0.202 \\
\hline CRP* (mg/L) & $0.3(0.2-0.8)$ & $0.4(0.3-$ & $0.8)$ \\
\hline $\begin{array}{l}\text { Sedimentation } \\
\text { (mm/hour) }\end{array}$ & $12(8-23)$ & $12(8-15)$ & 0.427 \\
\hline $\begin{array}{l}\text { Hemoglobin } \\
\text { (mg/dL) }\end{array}$ & $13.2 \pm 2.3$ & $13.7 \pm 2.6$ & 0.16 \\
\hline
\end{tabular}

\section{Medications}

\begin{tabular}{|l|c|c|c|}
\hline Clopidogrel,n(\%) & $20(20)$ & $12(12)$ & 0.123 \\
\hline $\begin{array}{l}\text { Acetylsalicylic } \\
\text { Acid, n(\%) }\end{array}$ & $81(81)$ & $72(72)$ & 0.133 \\
\hline B-blockers, (\%) & $77(77)$ & $68(68)$ & 0.154 \\
\hline $\begin{array}{l}\text { ACE* inhibitors, } \\
\text { (\%) }\end{array}$ & $46(46)$ & $35(35)$ & 0.113 \\
\hline ARB*, n(\%) & $24(24)$ & $19(19)$ & 0.389 \\
\hline CCB*, n(\%) & $31(31)$ & $23(23)$ & 0.203 \\
\hline Statins, n(\%) & $28(28)$ & $25(25)$ & 0.631 \\
\hline OAD*, n(\%) & $20(20)$ & $17(17)$ & 0.585 \\
\hline Insulin, n(\%) & $9(9)$ & $6(6)$ & 0.421 \\
\hline
\end{tabular}

ACE*: Angiotensin Converting Enzyme, ARB*: Angiotensin Receptor Blocker, BMI*: Body Mass Index, CAD*: Coronary Artery Disease, CCB*: Calcium Channel Blocker, CRP*: C- 
Reactive Protein, DPB*: Diastolic Blood Pressure, HDL*. High Density Lipoprotein, LDL*: Low Density Lipoprotein, OAD*: Oral anti-diabetic drug; SBP*: Systolic Blood Pressure

Table 2: Comparison of fundoscopic examination findings between patients with CAD and controls

\begin{tabular}{|c|c|c|c|}
\hline Fundoscopic Findings & $\begin{array}{c}\text { CAD } \\
\text { Group } \\
(\mathbf{n}=\mathbf{1 0 0})\end{array}$ & $\begin{array}{c}\text { Controls } \\
(n=100)\end{array}$ & $\begin{array}{c}\mathbf{P} \\
\text { value }\end{array}$ \\
\hline $\begin{array}{c}\text { Atherosclerosis, n (\%) } \\
\text { Grade I } \\
\text { Grade II } \\
\text { Grade III } \\
\text { Grade IV } \\
\end{array}$ & $\begin{array}{c}54(54) \\
32(32) \\
1(1) \\
0(0)\end{array}$ & $\begin{array}{c}39(39) \\
19(19) \\
0(0) \\
0(0)\end{array}$ & $<0.001$ \\
\hline $\begin{array}{l}\text { Hypertensive } \\
\text { Retinopathy, n (\%) } \\
\text { Grade I } \\
\text { Grade II } \\
\text { Grade III } \\
\text { Grade IV } \\
\end{array}$ & $\begin{array}{c}53(53) \\
30(30) \\
12(12) \\
0(0)\end{array}$ & $\begin{array}{c}33(33) \\
20(20) \\
7(7) \\
0(0)\end{array}$ & $<0.001$ \\
\hline $\begin{array}{l}\text { Diabetic Retinopathy, } \mathrm{n} \\
(\%)\end{array}$ & $8(8)$ & $6(6)$ & 0.579 \\
\hline $\begin{array}{l}\text { Retinal Vein Occlusion, } \\
\mathrm{n}(\%)\end{array}$ & $10(10)$ & $6(6)$ & 0.297 \\
\hline $\begin{array}{l}\text { Retinal Collateral } \\
\text { Vessels, n }(\%)\end{array}$ & $10(10)$ & $5(5)$ & 0.179 \\
\hline Retinal tortuosity, n (\%) & $65(65)$ & $57(57)$ & 0.246 \\
\hline $\begin{array}{l}\text { Hollenhorst plaques, } \mathrm{n} \\
(\%)\end{array}$ & $3(3)$ & $1(1)$ & 0.312 \\
\hline Drusenoid bodies, $\mathrm{n}(\%)$ & $52(52)$ & $42(42)$ & 0.157 \\
\hline
\end{tabular}

Grade III and IV atherosclerosis was not found. The prevalence of atherosclerotic changes was significantly higher in patients with CAD $(\mathrm{p}<0.001)$. Hypertensive retinopathy (HR) was found in $95 \%$ of the CAD patients and $\% 60$ of the controls which was also significantly different ( $p<0.001)$. Among patients with CAD, Grade I HR was found in 53\%, grade II HR was found in 30\% and grade III HR was found in $12 \%$ of the patients. Grade IV HR was not found. However, among control group, Grade I HR was found in 33\%, grade II HR was found in $20 \%$ and grade III HR was found in $7 \%$ of the patients. Grade IV HR was not found. Diabetic retinopathy was found in 8 patients with $\mathrm{CAD}$ and in 6 controls $(\mathrm{p}=0.579)$. HbA1c levels were significanly higher in patients with diabetic retinopathy $(p<0.001)$. There was no significant difference in terms of retinal vein occlusion (10 vs $6 \%, \mathrm{p}=0.297$ ), retinal collateral vessels (10 vs $5 \%$, $\mathrm{p}=0.179$ ), and increased retinal tortuosity (65 vs 57 $\%, \mathrm{p}=0.246$ ) between the groups. Drusenoid bodies were found in 52 patients with CAD and in 42 controls $(\mathrm{p}=0.157)$. Hollenhorst plaque was found in three patients with $\mathrm{CAD}$ and one among controls $(\mathrm{p}=0.312)$ (Figure1).

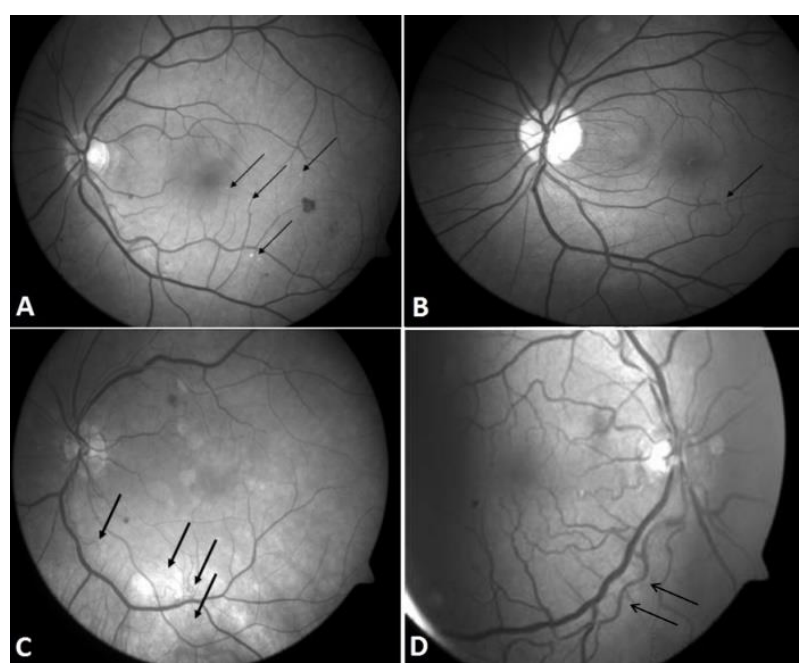

Figure 1. A: Drusenoid Bodies, B: Hollenhorst plaque, C: Venous collaterals, D: Retinal vascular tortuosity

Among fundoscopic findings, drusenoid bodies were found with a significantly higher rate in patients who were smokers $(\mathrm{p}<0.001)$. Similarly, drusenoid bodies were found with a statistically significantly higher rate in patients who were not using clopidogrel compared to the patients who were using clopidogrel $(\mathrm{p}<0.001)$.

\section{Discussion}

In this study we have focused on the relationship between the retinal findings and $\mathrm{CAD}$ by performing fundoscopic examination in patients diagnosed with CAD. The atherosclerotic and hypertensive retinal findings were more frequently observed in patients with CAD than the controls with similar risk factors. Therefore, fundoscopic examination may be useful in the evaluation of such patients with CAD.

Many studies have proposed that atherosclerotic changes found in the retina may be a marker of the prevalence of CAD (Tedeschi-Reiner et al., 2005). In a large-scale study, it was found that the risk of congestive heart failure was increased by three-fold in patients with retinopathy who had no CAD and hypertension (Torpy et al., 2005). In another study, the relationship of retinal vascular changes with left ventricular mass, left ventricular volume and concentric remodeling was investigated and it was stated that microvascular disease contributed to formation of cardiac remodeling by correlating with the risk factors of CAD (Cheung et al., 2007). In our study, Scheie classification was used in evaluation of atherosclerotic and hypertensive retinopathy (Scheie 1953). Our results showed that atherosclerotic and hypertensive retinopathy were closely related with the presence CAD similar to previous studies. Besides, the distribution of atherosclerotic retinopathy was similar to the 
distribution of hypertensive retinopathy in this study.

Point opacities were observed on the retinal surface in $52 \%$ and $42 \%$ of CAD patients and controls respectively. When fundus camera was used, it was thought that these opacities were drusenoid bodies (Figure 1A). It was thought that the drusenoid bodies which were found with a high rate in our study might be small drusens associated with age-related macula degeneration (ARMD) and/or particles located in the retina by way of extravasation of intravascular cholesterol crystals. ARMD is the most common reported cause of blindness in the population aged over 65 years old (Kelin 1999). In all studies, the prevalence of ARMD has shown an increase with age. Atherosclerosis in the carotid vascular bed, presence of systemic hypertension, smoking and dsylipidemia are risk factors for development of ARMD (Klein et al., 1993; Smith et al., 1996). Similarly, drusenoid bodies were found with a statistically significantly higher rate in patients who were smokers in our study.

The frequency of clopidogrel usage is increasing in the cardiovascular area. In previous studies, ASA and the other non-steroid antiinflammatory drugs were not shown to decrease the risk of ARMD (Christen et al., 2001). Similarly, no significant difference was found between the patients who were and were not using ASA in terms of drusenoid bodies in our study. However, these bodies were observed with a significantly higher rate in the patients who were not using clopidogrel compared to the patients who were using clopidogrel. If these bodies are considered drusen bodies related with ARMD, it may be thought that clopidogrel decreases development of ARMD in patients with a high risk in terms of CAD. In a study conducted by Cymerman et al. with young patients who had CAD, it was found that reticular macular disease which is a subtype of ARMD was observed commonly in middle-aged patients with CAD (Cymerman et al., 2016). In contrast to our study, it was emphasized that there was no significant correlation between $\mathrm{CAD}$ and drusen bodies. It was emphazsied that the relationship of reticular macular disease with $\mathrm{CAD}$ was related with subretinal drusenoid deposits found between the retinal pigment epithelium and internal segment ellipsoid region similar to the lipid mechanism in atherosclerosis (Cymerman et al., 2016). More and extended studies are needed to elucidate the relationship between reticular macular diseases and CAD.

As known, increased tortuosity in the arteries occurs as a result of aging or pathological changes in vascular elastic material (Ertugrul 1967; Soikkonen et al., 1991; Dobrin et al., 1998; Zegers et al., 2007). It has been reported that atherosclerosis, hypertension and aging play a role in development of arterial tortuosity (Leipzig and Dohrmann 1986; Weibel and Fields 1965; Del Corso et al., 1998). Increased tortuosity in the retinal arteries occurs as a result of aging or pathological chenges in vascular elastic material (Zegers et al., 2007; Del Corso et al., 1998). Increased tortuosity may also be observed in the retinal arteries. It is known that this is observed frequently especially in retinal pathologies including diabetic retinopathy, retinal vein occlusion and retinal vasculitis. In a previous study, a relationship was shown between increased cholesterol (especially increased triglyceride level) and blood pressure (risk factors for CAD) in the first 10 years of the childhood and tortuosity in the retinal arteries (Owen et al., 2011). Although the difference was not significant, the presence of retinal tortuosity in $65 \%$ of patients with CAD in our study supports this study.

One of the findings examined in our study was Hollenhorst plaques. Hollenhorst plaques are one of the most frequent causes of retinal emboli (Brown and Magargal 1982). These are orange, refractile cholesterol crystals with a length of $10-250 \mu \mathrm{m}$ and constitute the fundoscopic finding of Cholesterol Embolization Syndrome (CES) (David et al., 1963; Hollenhorst et al., 1962). In our study, Hollenhorst plaques were found in three patients with CAD. One of these patients had a history of thrombolytic treatment and the other one had a history of coronary bypass graft surgery. All three patients were hypertensive. Patients with Hollenhorst plaques on ophthalmologic examination are in the high risk group in terms of morbidity and mortality. The most appropriate mechanism explaining CES syndrome related with thrombolytic agents includes dissolving of protective thrombin coagulum with thrombolytic agents and release of cholesterol crystals because of subintimal hemorrhage (Scolari et al., 1996).

The primary limitation was that our study was a nonrandomized and single center study with a relatively small number of patients. Secondly, the severity of CAD was not evaluated quantitatively in patients with scoring systems such as Syntax or Gensini Scores. Comparison of the CAD severity with the prevalence of abnormal retinal findings would be clinically more meaningful. 


\section{Conclusion}

The atherosclerotic and hypertensive retinal findings were more frequently observed in patients with CAD than the controls with similar risk factors. Fundoscopic examination is a non-invasive method which can be performed easily in patients with CAD. Therefore, fundoscopic examination may be useful in the evaluation of such patients with CAD. Colloboration of cardiologists and opthalmologist in the evaluation of such patients with cardiovascular risk factors may profide a more efficient approach in diagnosis and treatment of CAD.

Ethics Committee Approval: Ethics committee approval was received for this study from Clinical Research Ethics Committee of Uludağ University Faculty of Medicine (2009-1/70).

Peer-review: Externally peer-reviewed.

Author Contributions: Concept - TD, OAS ; Design - TD, OAS ; Supervision TD, MK; Materials - TD, ÖY; Data Collection and/or Processing - TD, ÖY, MK,MY, LB, OÇ; Analysis and/or Interpretation - TD, MK,MY, LB, OÇ; Literature Review - TD, MK,MY, LB, OÇ; Writing - TD, MK, MY, LB, OÇ ; Critical Review - TD, MK, OAS

Conflict of Interest: No conflict of interest was declared by the authors.

Financial Disclosure: The authors declared that this study has /hasn't received no financial support.

\section{References}

Alberti KG, Zimmet PZ: Definition, diagnosis and classification of diabetes mellitus and its complications. Part 1: Diagnosis and classification of diabetes mellitus. Provisional report of a WHO consultation. Diabet Med 1988;15: 539-553

Baim DS, Grossmann W. Coronary Angiography. In: Baim Grossmann, editor. Grossman's Cardiac Catheterization, angiography, and Intervention. 6th ed. Philadelphia: Lippincott Williams and Wilkins; 2000; 211-57

Bonow RO, Smaha LA, Smith SC Jr, Mensah GA, Lenfant C. World Heart Day 2002: the international burden of cardiovascular disease: responding to the emerging global epidemic. Circulation 2002;106(13):1602-5.

Brown GC, Magargal LE. Central retinal artery obstruction and visual acuity. Ophthalmology. 1982;89(1):14-9.

Cheung N, Bluemke DA, Klein R, Sharrett AR, Islam FM, Cotch MF, Klein BE, Criqui MH,
Wong TY. Retinal arteriolar narrowing and left ventricular remodeling: the multi-ethnic study of atherosclerosis. J Am Coll Cardiol. 2007;50(1):48-55.

Christen WG, Glynn RJ, Ajani UA, Schaumberg DA, Chew EY, Buring JE, Manson JE, Hennekens $\mathrm{CH}$. Age-related maculopathy in a randomized trial of low-dose aspirin among US physicians. Arch Ophthalmol. 2001;119(8):1143-9.

Cymerman RM, Skolnick AH, Cole WJ, Nabati C, Curcio CA, Smith RT. Coronary Artery Disease and Reticular Macular Disease, a Subphenotype of Early Age-Related Macular Degeneration. Curr Eye Res. 2016 Nov;41(11):1482-1488.

David NJ, Klintworth GK, Frieldberg SJ, Dillon M. Fetal Atheromatous cerebral embolism associated with bright plaques in the retinal arterioles. Report of a case. Neurology. 1963; 13:708-13

Del Corso L, Moruzzo D, Conte B, Agelli M, Romanelli AM, Pastine F, et al. Tortuosity, kinking, and coiling of the carotid artery: expression of atherosclerosis or aging? Angiology 1998;49: 361-71.

Dobrin PB, Schwarcz TH, Baker WH. Mechanism of arterial and aneurysmal tortuosity. Surgery 1988;104:568-71.

Ertugrul A. Diffuse tortuosity and lengthening of the arteries. Circulation 1967;36:400-7.

Friedewald WT, Levy RI, Fredrickson DS. Estimation of the concentration of low-density lipoprotein cholesterol in plasma, without use of the preparative ultracentrifuge. Clin Chem. 1972;18(6):499-502

Goto I, Katsuki S, Ikui H, Kimoto K, Mimatsu T. Pathological studies on the intracerebral and retinal arteries in cerebrovascular and noncerebrovascular diseases. Stroke. 1975;6(3):263-9

Hollenhorst RW, Lensink ER, Whisnant JP. Experimental Embolization of the Retinal Arterioles. Trans Am Ophthalmol Soc. 1962;60:316-34.

Hubbard LD, Brothers RJ, King WN, et al. Methods for evaluation of retinal microvascular abnormalities associated with hypertension/sclerosis in the Atherosclerosis Risk in Communities Study. Ophthalmology 1999; 106: 2269-2280

Humphrey LL, Fu R, Rogers K, et al. Homocysteine level and coronary heart disease incidence: a systematic review and meta-analysis. Mayo Clin Proc 2008;83:1203e12 
Kelin R. Epidemiology. In age-related macular degeneration. In: Berger JW, Fine SL, Maguire MG. Eds. Philadelphia: Mosby; 1999;31-55.

Klein R, Klein BE, Linton KL, DeMets DL. The Beaver Dam Eye Study: the relation of agerelated maculopathy to smoking. Am J Epidemiol. 1993;137(2):190-200.

Leipzig TJ, Dohrmann GJ. The tortuosity or kinked carotid artery: pathogenesis and clinical considerations. Surg Neurol 1986;25: 478-86.

Owen CG, Rudnicka AR, Nightingale CM, Mullen R, Barman SA, Sattar N, Cook DG, Whincup $\mathrm{PH}$. Retinal arteriolar tortuosity and cardiovascular risk factors in a multi-ethnic population study of 10 year old children; the Child Heart And health Study in England. Arterioscler Thromb Vasc Biol. 2011 Aug;31(8):1933-8.

Scheie HG. Evaluation of ophthalmoscopic changes of hypertension and arteriolar sclerosis. AMA Arch Ophthalmol 1953; 49: 117-138

Scolari F, Bracchi M, Valzorio B, Movilli E, Costantino E, Savoldi S, Zorat S, Bonardelli S, Tardanico R, Maiorca R. Cholesterol atheromatous embolism: an increasingly recognized cause of acute renal failure. Nephrol Dial Transplant. 1996;11(8):1607-12.

Smith Jr SC. Current and future directions of cardiovascular risk prediction. Am J Cardiol 2006;97:28Ae32A

Smith W, Mitchell P, Leeder SR. Smoking and agerelated maculopathy. The Blue Mountains Eye Study. Arch Ophthalmol. 1996;114(12):151823.

Soikkonen K, Wolf J, Hietanen J, Mattila K. Three main arteries of the face and their tortuosity. $\mathrm{Br}$ J Oral Maxillofac Surg 1991; 29:395-8.

Tedeschi-Reiner E, Strozzi M, Skoric B, Reiner Z. Relation of atherosclerotic changes in retinal arteries to the extent of coronary artery disease. Am J Cardiol. 2005;96(8):1107-9.

Torpy JM, Glass TJ, Glass RM. JAMA patient page. Retinopathy. JAMA. 2005;293(1):128.

Weibel J, Fields WS. Tortuosity, coiling, and kinking of the internal carotid artery: etiology and radiographic anatomy. Neurology 1965;15:7-18.

Wilson PW, D'Agostino RB, Levy D, et al. Prediction of coronary heart disease using risk factor categories. Circulation 1998;97:1837e47

Wong TY, Klein R, Klein BE, Tielsch JM, Hubbard L, Nieto FJ. Retinal microvascular abnormalities and their relationship with hypertension, cardiovascular disease, and mortality. Surv Ophthalmol 2001; 46: 59-80.
Zegers ES, Meursing BT, Zegers EB, Oude Ophuis AJ. Oude Ophuis Coronary tortuosity: a long and winding road. Neth Heart J 2007;15:191-5. 